\title{
Systematic literature review of context-awareness applications supported by smart cities' infrastructures
}

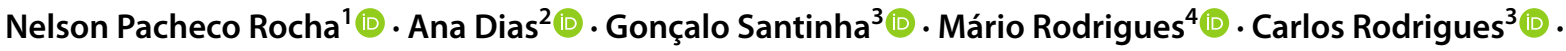

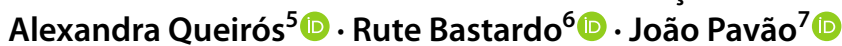

Received: 1 October 2021 / Accepted: 9 February 2022

Published online: 02 March 2022

(c) The Author(s) 2022 OPEN

\begin{abstract}
Since none of the existing systematic reviews of the literature related to smart cities have focused on smart cities applications using context-aware features, this study aims to provide a comprehensive view of (1) the characteristics of contextaware applications supported by smart cities' infrastructures, (2) the characteristics of the context-aware technologies being used, and (3) the maturity level of the identified applications. An electronic search was conducted on Scopus, Web of Science, and IEEE Xplore databases, combining relevant keywords. After the studies' selection, 27 studies were included. The results show the interest in using context-aware features to develop smart cities' applications targeting public health, tourism experience, urban mobility, active citizenship, shopping experience, management of urban infrastructures, public alerts, recommenders, and smart environments. Moreover, the applications reported by the included studies do not allow the execution of actions without the explicit consent of the users, and they integrate personal sensors, sensors deployed in the city and crowdsourcing mechanisms to acquire primary context attributes (i.e., location, activity, and environment) and secondary context attributes (i.e., speed, physical activity, points of interest, stress, and tourists' emotions). In addition, the included studies present scarce details about context reasoning, data privacy, integrity, and confidentiality, data aggregation and accuracy, and data interoperability. Finally, the results also indicate low maturity level of the developed applications, which is evidenced by the lack of user-centred evaluations, as well as by the difficulty in integrating important technologies being developed for smart cities.
\end{abstract}

Keywords Smart city · Context-aware applications · Systematic literature review

\section{Introduction}

The world of cities is changing and with it a wide range of quite trendy discourses and labels have emerged. From the computable or virtual city to the digital, the creative, the sustainable, the knowledge, the educating, the smart, the intelligent, the responsive, the ubiquitous or even the sentient city, all this labelling trend using the city metaphor is a result of a growing urbanization

$\triangle$ Nelson Pacheco Rocha, npr@ua.pt | ${ }^{1}$ Medical Sciences Department and Institute of Electronics and Informatics Engineering of Aveiro, University of Aveiro, Aveiro, Portugal. ${ }^{2}$ Department of Economics, Industrial Engineering, Management and Tourism \& GOVCOPP - Governance, Competitiveness and Public Policies, University of Aveiro, Aveiro, Portugal. ${ }^{3}$ Department of Social, Political and Territorial Sciences \& GOVCOPP - Governance, Competitiveness and Public Policies, University of Aveiro, Aveiro, Portugal. ${ }^{4}$ Águeda School of Technology and Management, Institute of Electronics and Informatics Engineering of Aveiro, University of Aveiro, Aveiro, Portugal. ${ }^{5} \mathrm{Health}$ Sciences School, Institute of Electronics and Informatics Engineering of Aveiro, University of Aveiro, Aveiro, Portugal. ${ }^{6}$ Science and Technology School \& UNIDCOM, University of Trás-Os-Montes and Alto Douro, Vila Real, Portugal. ${ }^{7}$ Science and Technology School \& INESC-TEC, University of Trás-Os-Montes and Alto Douro, Vila Real, Portugal. 
process and an increased global attention to build and develop competences to unravel emerging problems [1].

Cutting-edge information technologies (IT), entrepreneurship promotion, high capacity for learning and innovation, collective imagination of citizens in shaping and co-creating the city, and worldwide ecological balance are currently in the centre of public policy decisions and a flagship for the desired society. Coping with such challenges will lead to the veritable city, which Heynen [2] called Lutopia, as an allusion to how Leuven and many European cities will look in 2116.

But while waiting for the rise of Lutopia, the smart city tag is acting as a forerunner for these developments. In fact, when compared to other fashionable expressions, the smart city is at forefront of social discourse, policy making and research $[1,3,4]$, with several cities around the globe already claiming to be the smartest ones [5, 6]. There is no agreement, however, among scholars on what smart city means, with different indexes being published to rank cities $[5,6]$.

Building on the 'smart' combination of these domains, the use of IT, which serve as enabler of new favourable behaviours and environments, is an essential part of the puzzle [7]. Given the range of topics covered under the smart city concept, it has become a challenge to find an adequate organizing taxonomy $[1,8]$. Several studies have focused on the various dimensions of smart cities: (1) smart economy (competitiveness), smart people (social and human capital), smart governance (citizens' participation), smart mobility (transport), smart environment (natural resources) and smart living (quality of life) $[5,6] ;(2)$ urban openness, service innovation, partnerships formation, urban proactiveness, smart city infrastructure integration, smart city governance $[9,10] ;(3)$ technology, people (creativity, diversity, and education), and institutions (governance and policy) [11]; (4) management and organizations, technology, governance, policy context, people and communities, economy, built infrastructure, and natural environment [12]; (5) architecture, governance, planning and management, facilities, data and knowledge, services, people, and environment [13]; (6) technology, organization, collaboration, and experiment [14]; (7) economy, people, governance, environment, living, mobility and data [15]; and (8) smart business, smart living, smart education, smart citizen, smart government, smart infrastructure, smart utility, smart mobility, and smart environment [16]. In turn, the IEEE smart cities initiative $[17,18]$ proposed the smart water, smart energy, smart mobility, smart food and agriculture, smart health, and smart waste domains. Among these frameworks, the one proposed by Giffinger et al. $[5,6]$ was widely quoted $[19,20]$ and was used to frame different reviews (e.g., [21-24]).
A wide spectrum of IT is being considered to improve the smartness of cities, including efficient communication networks (e.g., the fifth generation or $5 G$ wireless networks), artificial intelligence, big data analytics, cloud computing and Internet of Things (IoT), among others [25, 26]. As a result, smart cities' applications are supported in a wide range of components for data generation, acquisition, management, and processing [27]. Since the goals and needs of the users of smart cities applications are time and space dependent [28], context-awareness mechanisms are required for collecting and processing contextual information to allow the applications to intelligently consider the conditions of their users and respective environments $[19,29]$.

Context-aware was first introduced by Schilit and Theimer [30: 22] as a software feature that "adapts according to its location of use, the collection of nearby people and objects, as well as changes to those objects". Other definitions emphasize the use of context information to provide relevant services, where relevancy depends on the characteristics of the users, the respective contexts and the tasks being performed [31]. A typical context-aware system has a dynamic nature and includes different activities that are repeated periodically, including the sensing of the users and environment (i.e., a sensing network is indispensable to obtaining accurate data) and the generation of proper reactions to operate the environment.

Since context-aware systems are self-adaptive, their development is always hard and complex. Furthermore, considering smart cities' applications, the difficulty level increases, due to requirements such as the scalability of the sensing networks, the difficulty of applying context recognition approaches based on knowledge [32], or the need to guarantee the data privacy, integrity, and confidentiality [33]. These challenges turn smart cities a singular application domain and specific context recognition approaches may be applied to it.

Due to the increasing development of smart cities' applications, it is important to understand how these applications integrate context-aware features. Concretely, the study reported by this article aimed to review and analyse the state-of-the-art of the context-aware applications supported by smart cities' infrastructures, and it is an extension of the review presented in [34], in terms of the number of studies reviewed (i.e., inclusion of studies published in 2020 and studies retrieved by a secondary analysis of the references of all the included studies) and the type of analyses that were performed (i.e., analysis of the common and distinct aspects of the articles included, instead of their descriptions).

This study might contributed to: (1) the systematization of the main recently published research on the topic; (2) the identification, typification, classification and discussion 
of relevant context-aware applications for smart-cities; (3) the identification of current approaches to use sensors and smart city data to support context-aware features; (4) the analysis of the maturity level of the reported applications; (5) the discussion about the main results and contributions of the current research; (6) the identification of the barriers to the dissemination of context-aware applications for smart-cities; and (7) the identification of the research gaps on the studied topic.

Several articles published in scientific journals $[1,3,10$, $25-28,32,33,35-56]$ reported different types of reviews, including systematic literature reviews, related to various aspects of smart cities' implementation: (1) bibliometrics (e.g., bibliometric analysis of the literature of the first decades of research on smart cities $[20,39]$ or identification of the conceptual dimensions and areas of smart cities based on bibliometric analysis [10]); (2) international standards (e.g., identification of relevant smart cities standards [48] or review of the standardisation activities that are being carried out by the United for Smart Sustainable Cities initiative [44]); (3) data analytics (e.g., the various data learning techniques being applied in smart cities [41] or big data applications to support urban environment, society, and sustainability [46]); (4) systems architectures (e.g., the contribution of the enterprise architecture towards digital transformation in smart cities [49]); (5) data security (e.g., identification of the barriers and hurdles in smart city and how these hurdles might be mitigated by the blockchain technology [45]); (6) loT and data analytics (e.g., identification of key areas of application, current trends, data architectures, and ongoing challenges of the application of loT and data analytics in smart cities [50]); (7) ontologies (e.g., how ontologies are being used to support smart city services [51]); (8) healthcare (e.g., relevant smart cities applications with impact in the provision of healthcare [42]); (9) energy efficiency (e.g., identification of the barriers to the progression to sustainable smart cities [52]), (10) citizenship (e.g., how public displays may foster citizen participation in addressing urban issues [23]); (11) smart city indicators (e.g., identification of potential indicators for implementing smart cities [22] or provision of a critical analysis of smart city assessment tools and their potential contribution to the evolution of the smart city movement [15]); (12) mobility (e.g., systematization of enabling technologies, current trends and solutions to support smart mobility [53] or smart city applications to facilitate the mobility of older adults in urban spaces [55]); and (13) age-friendly initiatives (e.g., conceptualization of the transport as one of the main domains of age-friendly cities as a core element of a smart, age-friendly ecosystem [47]). Looking specifically to context-awareness, it is possible to identify reviews that analyse context-aware technologies and their relation to loT (e.g., systematization of the most relevant research projects and commercial solutions of the first decade of this century [35]), recommender systems (e.g., relevant developmental processes for the research of context-aware recommender systems [38]), mobile sensing (e.g., research directions within context awareness for mobile platforms, namely in terms of localization, movement and activity tracking, and environmental sensing [40]) or vehicular applications (e.g., existing context-aware applications used in vehicular networks [37]). Moreover, it was recently published a systematic mapping aiming to investigate context recognition approaches applied in urban environments [32]. However, none of these reviews were focused on context-aware applications, which means that this study providing a comprehensive view of smart cities context-aware applications fills an existing gap of the literature reviews already published.

\section{Methods}

This systematic review followed the guidelines of the Preferred Reporting Items for Systematic Reviews and MetaAnalyses (PRISMA) [57]. To perform the systematic literature review, the authors defined a review protocol with explicit descriptions of the methods to be used and the steps to be taken [58]: (1) research questions; (2) search strategies; (3) inclusion and exclusion criteria; (4) screening procedures; (5) data extraction; (6) methodological quality assessment; and (7) synthesis and reporting.

\subsection{Research questions}

The objective of the systematic review reported by this article (i.e., to review and analyse the state-of-the-art of the context-aware applications supported by smart cities' infrastructures) was decomposed into the following research questions:

- RQ1-what is the state-of-the-art of the context-aware applications supported by smart cities' infrastructures?

- RQ2-what are the characteristics of the context-aware technologies being used?

- RQ3-what is the maturity level of the applications being reported?

\subsection{Search strategies}

In terms of resources to be searched three databases were considered. IEEE Xplore, a technological database, was selected together with two general databases, Web of Science and Scopus. The choice of IEEE Xplore was motivated by its importance among researchers who work in computer science related domains, a key aspect of the 
smart cities' developments. In turn, Web of Science and Scopus are the two major existing multidisciplinary databases, have a reputation of indexing quality peer reviewed research [59]. They have a high coverage of scientific journals and conference proceedings [60] and contain a significant number of references indexed by other databases, such as ACM Digital Library, Science Direct, SpringerLink or even IEEE Xplore. Moreover, Web of Science, Scopus and IEEE Xplore were considered, either alone, together or in conjunction with other databases, to support several reviews related to smart cities: Web of Science [15, 20,46]; Scopus [10, 28]; Web of Science and Scopus [24, 49]: Scopus and IEEE Xplore [52]; IEEE Xplore and Science Direct [53]; Scopus, IEEE Xplore, ACM Digital Library, Science Direct and Springer Link [50]; Scopus, Web of Science, Science Direct and Springer Link [39]; IEEE Xplore, ACM Digital Library, and Science Direct [22, 23, 45]. Google Scholar was not considered since the aim was to retrieve peer reviewed research.

Boolean queries were prepared to include all the articles that have in their titles, abstract or keywords a reference to smart city (e.g., 'SmartCity,' 'Smartcity', 'Smart-city', 'Smart Cities,' 'Smartcities' or 'Smart-cities') together with a reference to context-awareness (i.e., at least one of the following expressions 'context-aware','context aware,' 'context-awareness', or 'context awareness').

\subsection{Inclusion and exclusion criteria}

As inclusion criterion, the authors aimed to include peerreviewed studies that report evidence of explicit use of context-aware technologies in the development of applications supported by smart cities' infrastructures.

Articles were excluded if they: (1) did not have abstracts, (2) were not written in English; (3) their full texts were not available; (4) reported on reviews, surveys, or market studies; (5) were books, reported on workshops, or special issues announcements; (6) reported on studies that were not relevant for the objective of this systematic review; (7) reported on studies already covered by other articles (i.e., when two articles reported the same study in different venues, for instance, scientific journal and conference, the less mature one was excluded); and (8) were published after December 31, 2020.

\subsection{Screening procedures}

The selection of the articles to include in this systematic review was performed according to the following steps:

- First step - the authors removed the duplicates, the references without abstract or authors and not written in English.
- Second step-the authors assessed all titles and abstracts for relevance and those clearly not meeting the inclusion and exclusion criteria were removed.

- Third step - the authors assessed the full text of the remaining articles against the outlined inclusion and exclusion criteria.

- Fourth step-the authors performed a secondary analysis of the references of all the previous included articles to identify additional articles to be included.

Throughout this entire process, all articles were analysed by at least two authors and any disagreements between them were discussed and resolved by consensus.

From the screening procedures resulted a list of articles to be included in this systematic review (i.e., the included studies).

\subsection{Data extraction}

Concerning data extraction, the following information was registered in a data sheet prepared by the authors for each one of the included studies: (1) the demographics of the study (i.e., authors and respective affiliations, year and source of publication); (2) the scope of the study and the respective objectives; (3) the purpose of the smart city application being reported; (4) the adequacy of the context of the study; (5) the study research methods; (6) the findings of the study; (7) the limitations of the study; (8) details of the technologies being used, namely data sources, context-aware features and algorithms, or security mechanisms; and (9) the development stage of the application reported by the study.

\subsection{Methodological quality assessment}

In addition to general inclusion and exclusion criteria, the included studies were assessed against a set of six quality questions listed in Table 1, which were adopted and adjusted from other studies [61, 62]. Each question was answered according to a binary scale (i.e., 1 for Yes or 0 for No).

Table 1 Study quality assessment questions

\begin{tabular}{ll}
\hline$\#$ & Study quality assessment questions \\
\hline Q1 & Are the objectives of the study clearly identified? \\
Q2 & Is the context of the study clearly stated? \\
Q3 & Does the research methods support the aims of the study? \\
Q4 $\quad$ Has the study an adequate description of the technologies \\
\end{tabular}$\quad \begin{aligned} & \text { being used? } \\
& \text { Q5 }\end{aligned}$


A pilot test of three manuscripts was undertaken and results discussed to clarify potential differences regarding the understanding of process before moving to the assessment of the remaining studies. Then, for each study, at least two authors classify independently the six items of the methodological quality assessment scale. For each article, disagreements in any question of the scale were resolved by discussion until a consensus was reached.

\subsection{Synthesis and reporting}

Considering the demographics data, a synthesis of the characteristics of the included studies was prepared. This synthesis included: (1) the number of studies published in conference proceedings and scientific journals or as book chapters; (2) the distribution of the studies by year; (3) the trend of the publication rate, which was calculated using RMS Least Square Fit; and (4) the distribution of the studies by geographical areas, considering the affiliation of the first author.

Then, a table was prepared to synthesise the aims of the included studies. Moreover, to characterize the applications they were classified according to their purposes and contributions for the six domains of smart cities proposed by Giffinger et al. [5, 6]: (1) smart economy, competitiveness of the economy, including factors such as innovative spirit, entrepreneurship, ability to transform or integration in the international market; (2) smart people, social and human capital such as the level of qualification, fostering lifelong learning, ethnic plurality, and open mindedness; (3) smart governance, political strategies and perspectives, transparent governance, participation of the individuals in public life, and the quantity and quality of public services; (4) smart mobility, local, national, and international accessibility, and the availability of sustainable and safe transport systems; (5) smart environment, ecological awareness and sustainable management of natural resources; and (6) smart living, quality of life of the individuals, namely health conditions, cultural and education facilities, housing quality, and touristic attractiveness.

Since the existence of contextual information is the basis for the reasoning supporting context-awareness, the data gathering is an important issue of the proposed applications. Moreover, considering the different definitions of context-aware proposed by different authors $[31,63]$, in this systematic review, the adopted definition was the one proposed by Dey [63:6]: "A system is context-aware if it uses context to provide relevant information and/or services to the user, where relevancy depends on the user's task", which was useful to identify context-aware systems from the rest. In turn, to characterize the users' interaction, three levels of context-awareness were considered [31]: (1) personalization (i.e., the users set their preferences and expectation to the system manually); (2) passive (i.e., the system constantly monitors the environment and offers the appropriate options to the users so they can take actions); and (3) active (i.e., the system continuously monitors the situation and acts autonomously). Moreover, Abowd et al. [31] distinguished between primary context attributes and secondary context attributes. Primary context attributes characterize both the individuals (e.g., identity, location, activity, and time) and the environment (e.g., weather conditions) [31, 35]. In turn, secondary context attributes can be inferred using data fusion operations [31]. Finally, context reasoning comprises different techniques to process and interpret the context attributes in the light of previous knowledge, so that actions can be taken by the applications according to the needs and preferences of their users.

Since personal data are used by context-aware applications, mechanisms to guarantee the data privacy, integrity, and confidentiality are required. Also, there is the need to use huge amount of data from different sources, which means that data accuracy, standardization and interoperability are key aspects [51].

Therefore, to characterize the context-aware technologies being used, the included studies were analysed in terms of types of the data sources, context-aware features, and data security and aggregation: (1) tabular syntheses were prepared for the types of the data sources, including continuous data gathered by the personal sensors that are gradually being pushed into the market, data acquired from the smart city infrastructures, data generated by human observation (e.g., crowdsensing), and smarty cities' data repositories (e.g., tourism or public transports information); (2) based on the context-aware definitions, a narrative and tabular synthesis of the context-aware features was performed, which also included the algorithms (e.g., machine learning algorithms) required to process context attributes, to infer knowledge, and to make predictions so that correct actions can be performed [64]; and (3) a narrative synthesis was performed to identify technologies used by the included studies for providing data aggregation, security and interoperability.

In order to evaluate the maturity level of the solutions being reported, in addition to the analysis of the technologies being used, the authors distinguished the following development stages: (1) requirements-the study included the requirements' elicitation, which could involve, in some cases, forms of co-design with potential end users; (2) design-the focus of the study was a general overview of the application architecture or some of the respective components; (3) technical testing - the study included results of a performance evaluation of the application or some of its components (e.g., the performance of a specific algorithm); 
(4) prototype testing - the study included a laboratory evaluation involving end users (e.g., a usability evaluation) of a minimally working version of the application being proposed; (5) pilot testing - the study included a real-world evaluation by end users in their daily context during a certain period; and (6) mature-the study included an application that has been tested by end users, amended in some way and that is ready for deployment. Additionally, an analysis of the aims and methods of the experiments involving end users was also performed.

\section{Results}

\subsection{Selection of the studies}

Figure 1 presents the PRISMA flowchart of the systematic review. The electronic literature search was performed in July 2021 and aimed to include articles published before December 31, 2020. A total of 631 articles were retrieved: (1) 302 from Scopus; (2) 174 from Web of Science; and (3) 155 from IEEE Xplorer.

The first step of the screening procedures yielded 288 articles, since 343 were removed because they (1) were duplicated (i.e., 300), (2) did not have abstracts (i.e., four),

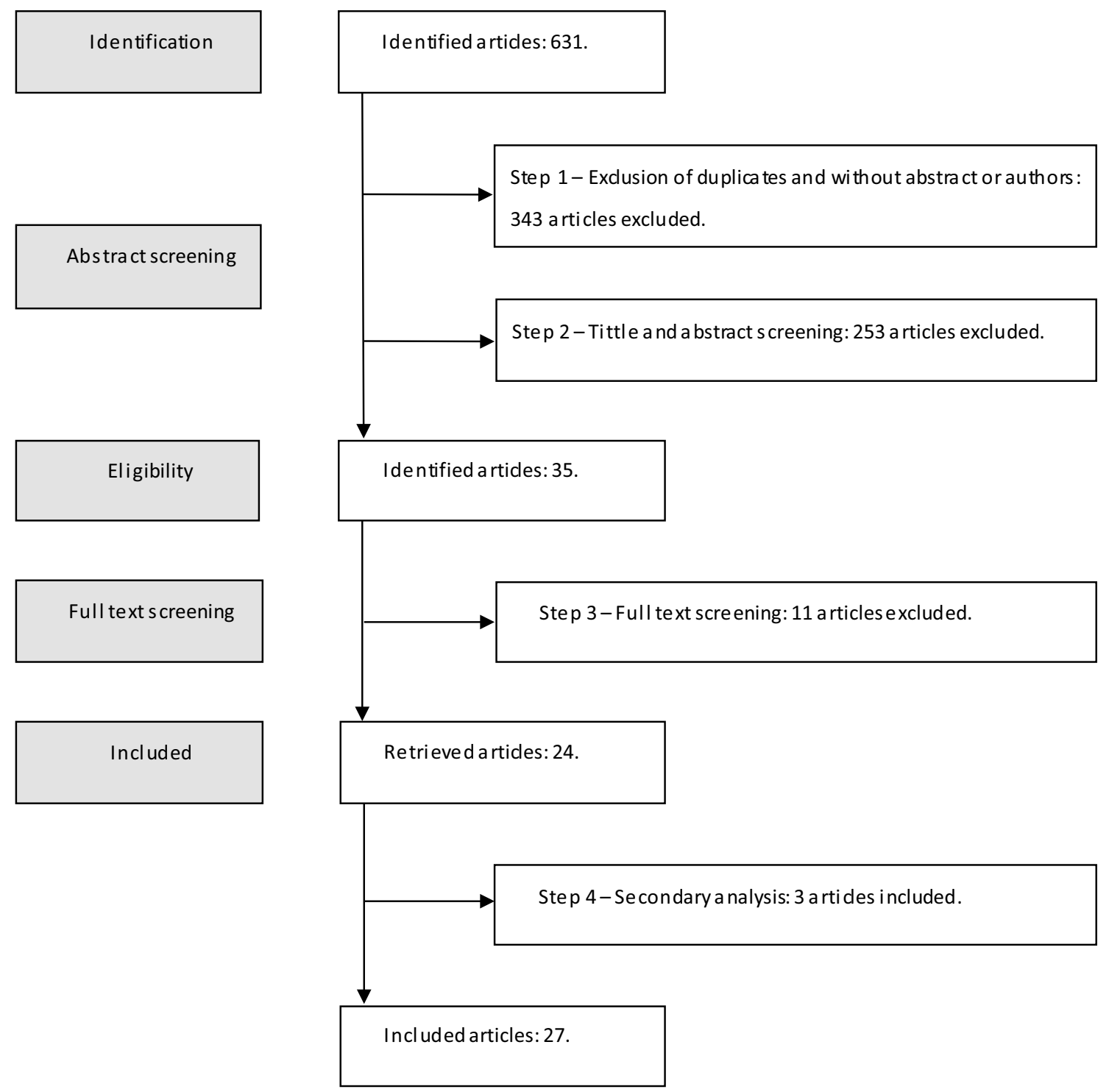

Fig. 1 PRISMA flowchart of the systematic review 
or (3) did not have authors and their abstracts were the contents of conference proceedings (i.e., 39).

During the second step, two references were excluded because they were retraction notes and another 251 were removed, because they (1) reported on reviews or surveys (i.e., 36), and (2) were not relevant for the objective of this systematic review (i.e., 215), since they were out of scope (e.g., [65-71]), or despite being focused on context-awareness and smart cities, did not present specific applications (e.g., [72-78].

Finally, after the full text analysis (i.e., the third step) eight articles were removed since they did not meet the inclusion and exclusion criteria. Furthermore, since, three studies were reported twice, three more articles were excluded [79-81] (i.e., the less mature report of each one of the three studies).

During the fourth step (i.e., a secondary analysis of the references of all the previous included articles) three more articles were identified.

Therefore, the final list of the retrieved articles contained 27 studies [82-108] that were included in this systematic review.

\subsection{Demographics of the studies}

In terms of publication types, 17 studies were published in conference proceedings [82-84, 87, 89-92, 94, 97-100, 102-105], nine studies were published in scientific journals $[85,86,88,93,95,96,101,107,108]$ and one study was published as a book chapter [106].

Concerning the publication years, the included studies were published between 2012 (i.e., one study [82]) and 2020 (i.e., four studies [105-108]). Moreover, as shown by the diagram of Fig. 2, 74\% of the studies (i.e., 20 studies [89-108]) were published since 2017 and there is a trend towards an increasing number of publications over the years.

Analysing the distribution of the included studies by geographical areas, Europe has the highest contribution (i.e., 15 studies), followed by Asia (i.e., eight studies). Comparatively, the remaining regions of the world have relatively residual contributions: together, North America, Africa and Oceania contributed with four studies. Moreover, only five studies involved the participation of multinational teams: (1) Canada and Saudi Arabia [82]; (2) Japan, German, and Russia [96]; (3) Sweden, Australia, and Russia [103]; (4) Pakistan and Saudi Arabia [106]; and (5) Algeria and France [107].

\subsection{Methodological quality assessment}

The results of the methodological quality assessment of the included studies are present in Fig. 3. All studies stated the aims and objectives of the conducted research (Q1. are the objectives of the study clearly identified?). In turn, only six studies explicitly included the methods that supported the research $(\mathrm{Q} 3$. does the research methods support the aims of the study?), and only five studies discuss the limitation of their results (Q6. Are limitations of the study discussed explicitly?). The results for the remainder three questions of the methodological quality assessment were 19 (Q5. is there a clear statement of the findings?), 14 (Q2. is the context of the study clearly stated?) and 12 (Q4. has the study an adequate description of the technologies being used?).

\subsection{Characteristics of the context-aware applications supported by smart cities' infrastructures}

Table 2 presents the purposes of the applications reported by the included studies. Some applications were developed aiming to contribute for the solution of a specific problem [84, 87, 93-95, 97, 99, 101, 103, 104]. However, other studies aimed the development of applications as examples of applicability of specific architectures, models, or components (e.g., contextaware architectures, queue management architectures,
Fig. 2 Studies by year and publication rate (calculated using RMS least square fit)
Articles by year and publication rate

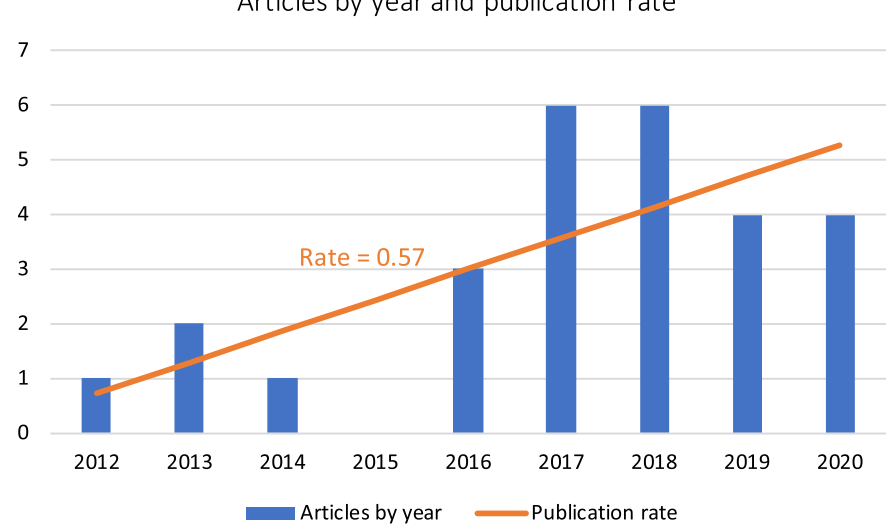


Fig. 3 Methodological quality assessment of the included studies

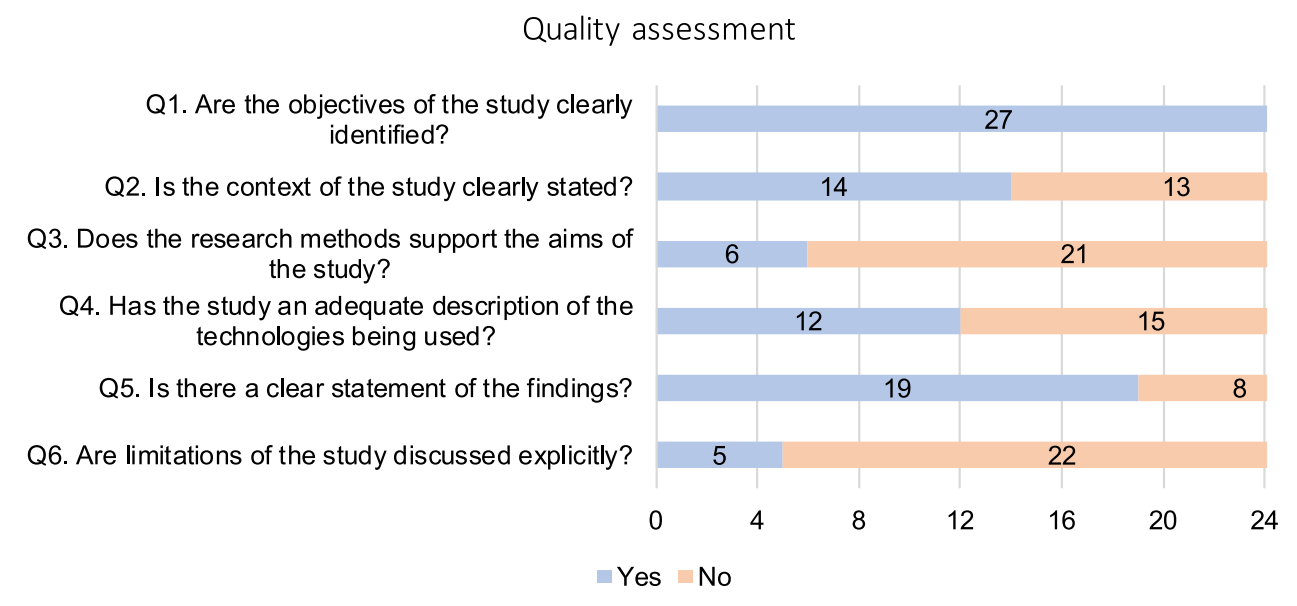

Table 2 Purposes of the applications presented by the included studies

\begin{tabular}{|c|c|c|}
\hline References & Aim & Year \\
\hline [82] & An application to assist drivers & 2012 \\
\hline [83] & A polling mobile application & 2013 \\
\hline [84] & An application to provide public alerts & 2013 \\
\hline [85] & $\begin{array}{l}\text { An application to promote the role of the citizens as collectors of data to inform the development and utilization of the } \\
\text { urban services }\end{array}$ & 2014 \\
\hline [86] & $\begin{array}{l}\text { An application aiming to stimulate the active participation of citizens in generating and sharing useful comments } \\
\text { related to the quality of air }\end{array}$ & 2016 \\
\hline [87] & $\begin{array}{l}\text { An application that gathers contextual information and displays a map with an approximate distribution of free parking } \\
\text { areas nearby to the users' position }\end{array}$ & 2016 \\
\hline [88] & A logistic application to guarantee that delivery items are held under proper environmental conditions & 2016 \\
\hline [89] & An application to assess real-time congestion on roads & 2017 \\
\hline [90] & A participatory sensing application & 2017 \\
\hline [91] & An application aiming the improvement of shopping experience & 2017 \\
\hline [92] & An application to help their users to avoid walking through noisy areas & 2017 \\
\hline [93] & An application able to offer personalized recommendations of exercise routes according to the users' health condition & 2017 \\
\hline [94] & An application aiming to provide multi-type recommendations & 2017 \\
\hline [95] & $\begin{array}{l}\text { An air quality monitoring application aiming to submit personalized alerts whenever air quality-related health risks are } \\
\text { detected }\end{array}$ & 2018 \\
\hline [96] & $\begin{array}{l}\text { An application to determine emotional status and satisfaction level of tourists during sightseeing by using unconscious } \\
\text { and natural tourist actions }\end{array}$ & 2018 \\
\hline [97] & An audio augmented reality application for providing informative tourism services and engaging experiences & 2018 \\
\hline [98] & An application to provide tourism recommendations & 2018 \\
\hline [99] & A pollution monitoring and alert application that proactively notifies citizens about air quality & 2018 \\
\hline [100] & Intelligent traffic management application & 2018 \\
\hline [101] & A parking application to assist drivers in finding parking slots dynamically while moving or arriving at the destination & 2019 \\
\hline [102] & An application able to recommend contents and services according to context and users' profile & 2019 \\
\hline [103] & $\begin{array}{l}\text { An application to give daily proactive recommendations for appropriately rescheduling the waste collection day in pres- } \\
\text { ence of problematic weather events }\end{array}$ & 2019 \\
\hline [104] & An application for promoting physical activity among older adults & 2019 \\
\hline [105] & An application to monitor air quality & 2020 \\
\hline [106] & A recommender application for smart markets & 2020 \\
\hline [107] & $\begin{array}{l}\text { An application to provide a smart environment that can be adapted according to the user's agenda and the contextual } \\
\text { information retrieved from mobile devices }\end{array}$ & 2020 \\
\hline [108] & An application to provide individual air quality indexes & 2020 \\
\hline
\end{tabular}


location-based components, social-aware components, or ontologies). Moreover, in general, the requirements of potential target users were not reported.

Based on the analysis of the purposes of the applications being developed, the following application types were identified:

- Public health, six studies [93, 95, 99, 104, 105, 108]: (1) two studies $[93,104]$ focused on the promotion of healthy lifestyles by developing recommenders that make use of smart cities' infrastructures; and (2) four studies $[95,99,105,108]$ included context-aware applications that proactively notify citizens via mobile devices about air quality once they enter an area with air pollution that exceeds user defined thresholds.

- Tourism experience, four studies [96-98, 102]: (1) audio augmented reality tour guides [97], (2) tourism recommendations [98]; (3) personalized stories of the places to visit [102]; and (4) estimates of the emotional status and satisfaction level of tourists during sightseeing [96].

- Urban mobility, seven studies $[82,87-89,92,100,101]$ : (1) navigation support [82, 87, 92]: (2) parking support $[87,101]$; (3) tools to optimize the traffic management in the urban environments $[89,100]$; and (4) management of logistic vehicles [88].

- Active citizenship, four studies [83, 85, 86, 90]: (1) using social context to stimulate the creation of discussions between citizens on topics related to air quality [86]; (2) providing polling mechanisms to enable public municipalities to leverage citizen involvement in decision-making processes [83]; (3) providing citizens with mechanisms to report security events or crimes [85]; and (4) allowing the creation, execution of contextaware, multi-purpose participatory sensing campaigns, and analysis of the results [90].

- Shopping experience, two studies [91, 106]: (1) using sensing and context-aware technologies to manage the customer flows in stores [91]; and (2) offering context-aware recommendations for smart markets.

- Management of urban infrastructures, one study [103], which developed a reasoning model to give proactive recommendations for appropriately rescheduling the waste collection day in presence of problematic weather events.

- Public alerts, one study [84], which provided public alerts based on the aggregation of various data sources, including social web feeds.

- Recommenders, one study [94], which developed an application to provide different types of recommendations (e.g., hospital, gas station, restaurant, attraction, and cinema).

- Smart environment, one study [107], which developed an application to provide a smart environment that can be adapted according to the users' agendas and contextual information.

Therefore, considering the six smart cities' domains defined by Giffinger et al. [5, 6], all the domains are present, except the smart people domain (Fig. 4): (1) smart economy, two studies [91, 106]; (2) smart governance, five studies [83-86, 90]; (3) smart mobility, seven studies [82, 87-89, 92, 100, 101]; (4) smart environment, seven studies $[86,92,95,99,103,105,108]$; and (5) smart living, 13 studies [92-99, 102, 104, 105, 107, 108]. It should be noted that six studies were mapped in more than one domain, according to the purposes of their applications (i.e., [86, $92,95,99,105,108])$.

\subsection{Characteristics of the context-aware technologies being used}

The data being used by automated and intelligent processes, including context-aware processes, come from different data sources. As shown in Fig. 5, personal sensors (i.e., sensors deployed in mobile devices and wearables) were used by $75 \%$ of the studies, while sensors deployed

Fig. 4 Distribution of the studies according to the smart city domains
Distribution of the studies according to smart city domains

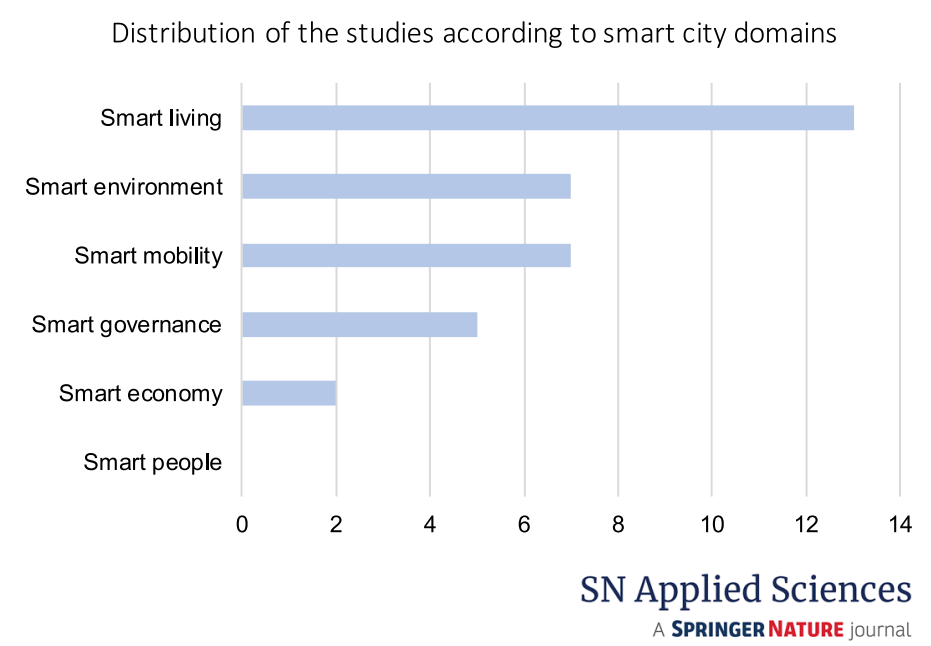


Fig. 5 Percentage of the studies reporting the use of the personal sensors, sensors deployed in the city, and both personal sensors and sensors deployed in the city

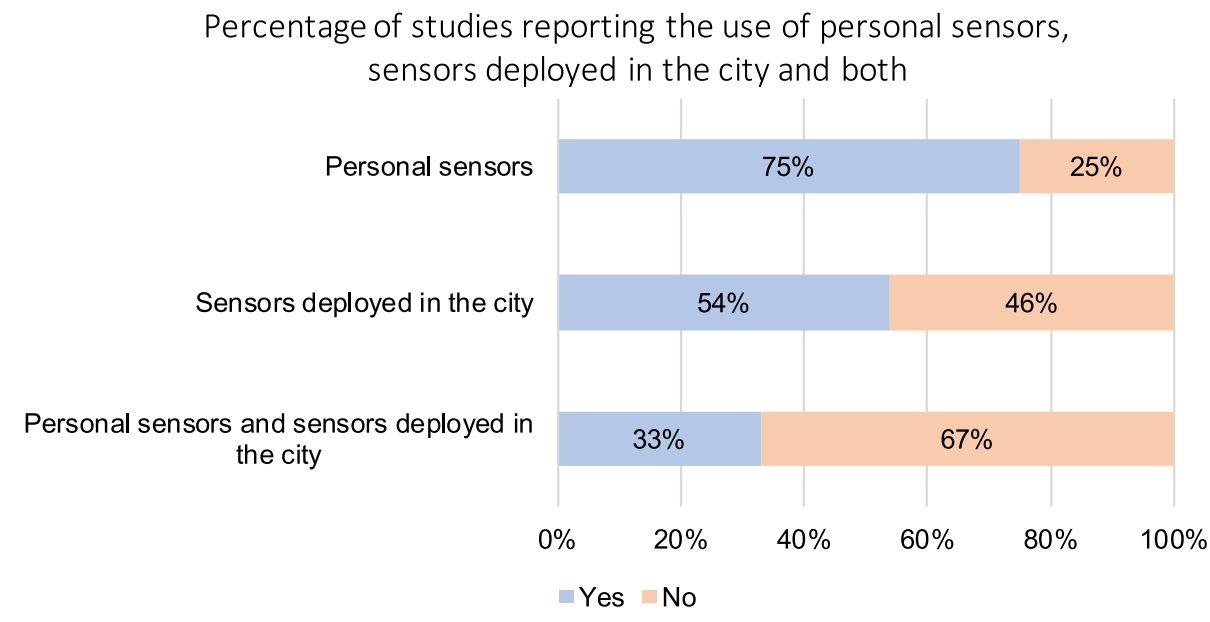

Table 3 Types of personal sensors being used by the proposed applications

\begin{tabular}{lc}
\hline Types of sensors & References \\
\hline Smartphones' sensors & \\
Unspecified & {$[86,87,93$,} \\
& $97,98,107$, \\
& $108]$ \\
Cell-ID & {$[83]$} \\
Gyroscopes and accelerometers & {$[92,104,106]$} \\
Global positioning system (GPS) & {$[83-85,89$,} \\
& $90,92,95$, \\
& $96,99,104$, \\
Wi-Fi & $106]$ \\
Luminosity & {$[83]$} \\
Audio sensors & {$[90,92]$} \\
Video cameras & {$[90,96]$} \\
Wearables & {$[96]$} \\
Body area network & \\
Physical activity sensor & {$[104]$} \\
Eye-gaze tracker & {$[96]$} \\
\hline
\end{tabular}

in the city were used by $54 \%$ of the studies. Only $33 \%$ of the studies used both personal sensors and sensors from the smart city infrastructure. Figure 5 is complemented by Tables 3 and 4, which respectively present the types of personal sensors and sensors deployed in the city that were identified in the included studies.

Moreover, four studies implemented crowdsourcing mechanisms (Table 5) and two-thirds of the studies reported the integration of data from smart city databases (Table 6), namely local repositories, repositories of data submitted by the citizens (e.g., tweets about incidents), environmental conditions and city routes.

Looking at the technological details presented by the included studies, only six studies considered the concept
Table 4 Types of sensors deployed in the cities being used by the proposed applications

\begin{tabular}{ll}
\hline Types of sensors & References \\
\hline Sensors of deployed in vehicles & \\
Unspecified & {$[82,89,100]$} \\
GPS & {$[89]$} \\
Sensors of deployed in the cities & \\
Unspecified & {$[82,86,88,89,92,93$,} \\
& $95,100,101,105$, \\
Particulate matter sensors & $108]$ \\
Video cameras & {$[99]$} \\
Thermal cameras & {$[87,89,91]$} \\
Radio-frequency identification (RFID) & {$[91]$} \\
GPS & {$[82,89]$} \\
\end{tabular}

Table 5 Studies using crowdsourcing

\begin{tabular}{ll}
\hline References & Aims \\
\hline$[85]$ & $\begin{array}{l}\text { To identify safety incidents } \\
\text { To collect and share data related to the } \\
\text { environmental conditions of the city }\end{array}$ \\
$\begin{array}{l}\text { To conduct participatory sensing campaigns } \\
{[90]}\end{array}$ & To determine the quality of the city routes \\
\hline
\end{tabular}

Table 6 Data from the smart cities' databases

\begin{tabular}{ll}
\hline Type of data & References \\
\hline Local repositories & {$[85,92,98,102]$} \\
$\begin{array}{l}\text { Repositories of citizens' submitted } \\
\text { data }\end{array}$ & {$[85,89,90,92,98]$} \\
Environmental conditions & {$[86,89,92,94,98,105,108]$} \\
City routes & {$[93,104]$}
\end{tabular}


Table 7 Primary context attributes acquired by personal sensors

\begin{tabular}{|c|c|c|c|}
\hline Types of sensors & Location & Activity & Environment \\
\hline \multicolumn{4}{|l|}{ Smartphones'sensors } \\
\hline Unspecified & $\begin{array}{c}{[86,87,93,97,98,} \\
107,108]\end{array}$ & {$[87,97]$} & \\
\hline Cell-ID & [83] & [83] & \\
\hline Gyroscopes and accelerometers & & {$[92,104,106]$} & \\
\hline GPS & $\begin{array}{c}{[83-85,89,90,92,95} \\
96,99,104,106]\end{array}$ & $\begin{array}{l}{[83,89,92,95,96,104,} \\
\quad 106]\end{array}$ & {$[90]$} \\
\hline Wi-Fi & [83] & [83] & \\
\hline Audio sensors & & [96] & \\
\hline Camera & & [96] & \\
\hline \multicolumn{4}{|l|}{ Bluetooth low energy beacons } \\
\hline \multicolumn{4}{|l|}{ Wearables } \\
\hline Body area network & & {$[96,104]$} & \\
\hline Eye-gaze tracker & & {$[96]$} & \\
\hline
\end{tabular}

Table 8 Primary context attributes acquired by sensors deployed in the city

\begin{tabular}{|c|c|c|}
\hline Types of sensors & Location & Environment \\
\hline \multicolumn{3}{|l|}{ Sensors of deployed in vehicles } \\
\hline Unspecified & & {$[88,89]$} \\
\hline GPS & & [89] \\
\hline \multicolumn{3}{|c|}{ Sensors of deployed in the cities } \\
\hline Unspecified & & $\begin{array}{c}{[82,86,89,} \\
92-95,101, \\
105,108]\end{array}$ \\
\hline Particulate matter sensors & & [99] \\
\hline Video cameras & & {$[87,89,91]$} \\
\hline Thermal cameras & & {$[91]$} \\
\hline RFID & & [89] \\
\hline GPS & {$[91,103]$} & \\
\hline
\end{tabular}

of IoT, although just two studies referred the protocols being used.

Despite in some cases it is possible to customize the applications (i.e., personalization [31]), through the insertion of data (e.g., user profiles [84, 95, 98], preferences [93, $94,104]$, health conditions [104], fixed location or fixed activity schedule [95]), all the applications of the included studies do not allow the execution of actions without the explicit consent of the user (i.e., they are passive applications [31]), which means they present suggestions, and it is up to the users to accept or not those suggestions.

Tables 7 and 8 present the different primary context attributes considered by the included studies using sensors of personal devices (i.e., Table 7) or sensors deployed in the city (i.e., Table 8).

Analysing the included studies, location and activity of the users are important context attributes. Except for the applications reported by $[91,94,101-103,105]$, in all other studies smartphones are used to locate or identify activities of the users. Moreover, in one study [103] a smart bin able to provide its location was considered and, in another study, [91], various location mechanisms are used to infer customers' queues length, including video cameras or Bluetooth and GSM activities.

Additionally, some of the described applications also use secondary attributes, including speed [89], physical activity [96, 104], points of interest [90], stress [91], and tourists' emotions [96].

Table 9 presents the type of data collected by the applications of the included studies to characterize the environment. Different measurements are considered,
Table 9 Data collected by the applications of the included studies to characterize the environment

\begin{tabular}{lll}
\hline Environment attributes & $\begin{array}{l}\text { Sensors of deployed in } \\
\text { vehicles }\end{array}$ & Sensors of deployed in the cities \\
\hline $\begin{array}{l}\text { Vehicles: presence, number, speed, } \\
\quad \text { and occupancy }\end{array}$ & {$[89]$} & {$[87,89,100,101]$} \\
Number of individuals & {$[91]$} \\
Air quality & {$[86,93,95,99,105,108]$} \\
Weather conditions & {$[86,88,89,92-94]$} \\
Luminosity & {$[82,92]$} \\
\hline
\end{tabular}


namely presence, number, speed and occupancy of vehicles, number of individuals, air quality, weather conditions, and luminosity.

The technical details of the context reasoning are scarce, since only six studies reported on the algorithms being used [89, 96, 99, 103, 106, 108]: (1) in [89] a Dynamic Bayesian Networks was used to deal with time-series data and uncertainties; (2) [96] reported on the development of a model for quantitatively estimating both emotion and satisfaction employing multiple modalities; (3) [99] reported on the development of an algorithm for the extraction of critical areas from air quality measurements; (4) [108] adopted a Deep Learning Neural Network approach for air quality prediction; (5) in [103] a reasoning algorithm decided whether it is more efficient to perform the day waste collection for a certain area or not; and (6) [106] reported on the development of an algorithm to dynamically calculate the relevant products considering the clients' location and preferences.

Finally, data privacy, integrity, and confidentiality are considered by six studies $[83,85,90,92,99,104]$, but only three studies presented details (i.e., high-level details) of the security mechanisms $[83,85,90]$.

In turn, mechanisms to aggregate data from different sensors and to guarantee the accuracy of these data were considered by three studies $[85,91,99]$. Also, three studies $[85,89,104]$ considered the need of data interoperability. However, the technical reports related to both data accuracy and interoperability are scarce and vague. For instance, [104] referred to the intention to use Fast Healthcare Interoperability Resources (FHIR) for the interoperability of healthcare data, [89] referred to the intention of applying standards and developing wrappers and adapters to enable flow of information between multiple applications, and [89] referred to the need to represent the data in a common machine-readable format such as Resource Description Framework (RDF) for data interoperability.

\subsection{Maturity level of the applications being reported}

Concerning the development stages of the included studies (Table 10), two studies were classified as requirements and four studies as design stage. The remainder studies were classified as technical testing (17 studies), prototype testing (three studies), and pilot testing (one study). None of the studies were classified as mature.

As can be seen in Fig. 6, which presents the number of studies by maturity level over the years, the most mature solutions are not associated to more recent years (e.g., in 2021 only solutions classified as technical testing were identified).
Table 10 Maturity level of the proposed solutions

\begin{tabular}{ll}
\hline Maturity level & References \\
\hline Requirements & {$[83,85]$} \\
Design & {$[90,91,101,104]$} \\
Technical testing & {$[82,84,87-89,92,93$,} \\
& $95,98-100,102,103$, \\
& $105-108]$ \\
Prototype testing & {$[86,94,97]$} \\
Pilot testing & {$[96]$} \\
Mature & None \\
\hline
\end{tabular}

Looking specifically to the studies that performed prototype or pilot testing involving end users, in [86] 19 participants (mainly university students) were recruited for an one day evaluation session to provide reactions and suggestions, [94] reported a survey based on a special purpose questionnaire and involving 50 random participants, in [97] a usability evaluation using System Usability Scale was conduct with 12 participants, and, finally, in [96] an experiment was conduct with 22 participants to evaluate the accuracy of the application.

\section{Discussion}

Concerning the first research question (i.e., the state-ofthe-art of the context-aware applications supported by smart cities' infrastructures), we may conclude that there is a current interest (i.e., $74 \%$ of the included studies were published since 2017) to develop applications to support public health, tourism experience, urban mobility, active citizenship, shopping experience, management of urban infrastructures, public alerts, recommenders, and smart environments. These purposes are also present in current smart city research, since urban mobility, healthcare, public safety, social, economic and environmental dimensions of sustainability, services' efficiency and governance, namely participatory governance involving the citizens, are important topics of the smart city research agenda $[10,19,20]$. In fact, except smart people, all the remainder smart city domains defined by Giffinger et al. [5, 6] (i.e., smart economy, smart governance, smart mobility, smart environment, and smart living) are present in the included studies.

With respect to the characteristics of the context-aware technologies being used (i.e., the second research question), all the included studies have passive context-aware applications, some applications can be personalized, but there are no studies with active context-aware applications. In turn, in terms of primary context attributes, a group of studies implemented location recognition while 


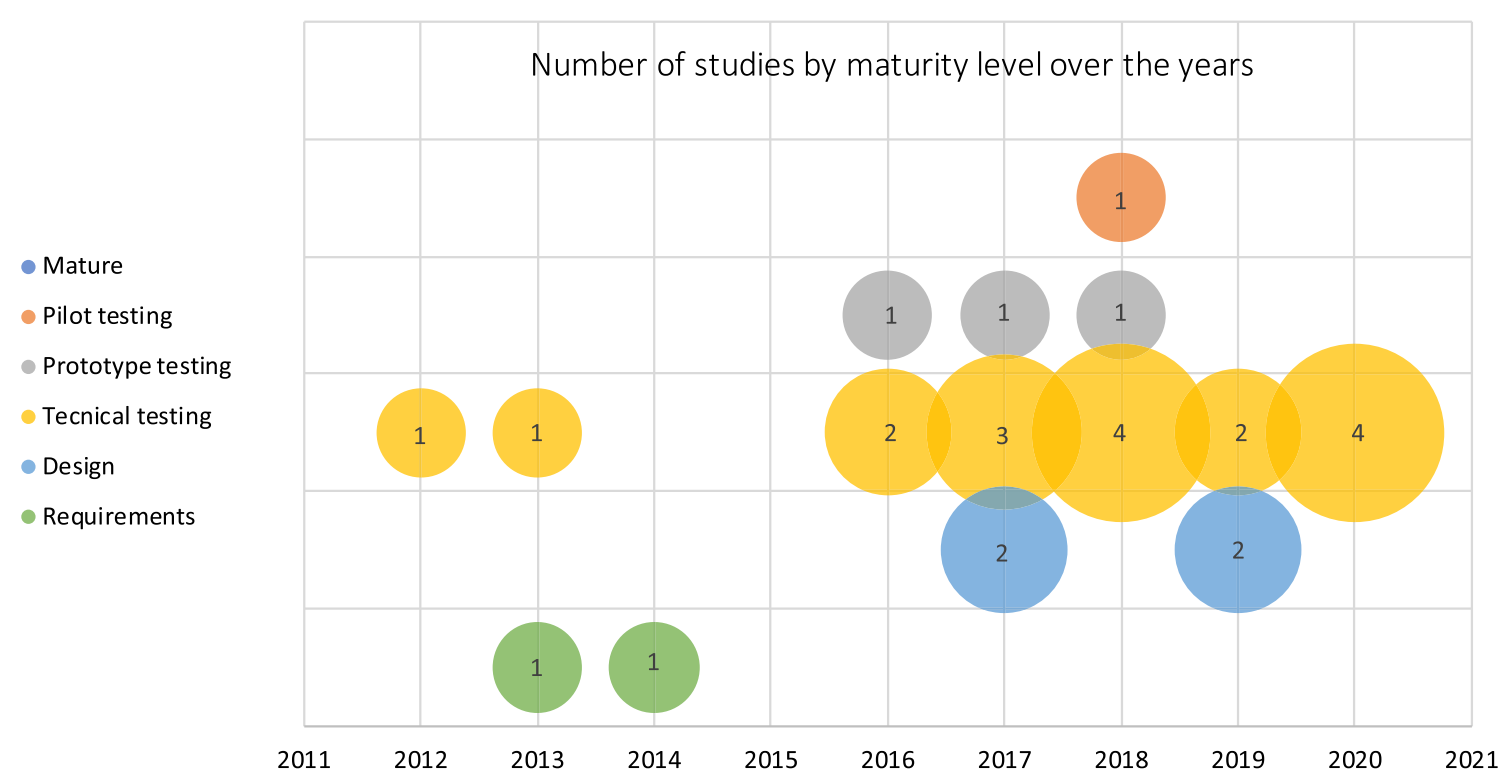

Fig. 6 Number of studies by maturity level over the years

another group implemented both the recognition of the location and the activity. Still in terms of primary context attributes, more than half of the studies considered the characterization of the environment (e.g., weather conditions or luminosity). In turn, secondary context attributes were also considered by some studies, including speed, physical activity, points of interest, stress, tourists' emotions, or the number of individuals inside a store.

To support context-aware reasoning the included studies reported the use of data acquired from the smart city infrastructure, such as air quality, weather conditions, or light conditions, and data available in the smart city databases, namely repositories of citizens' submitted data, environmental conditions, and city routes. On the other hand, sensors deployed in citizens mobile devices and wearables were used to acquire primary context attributes such as location and activity, and to infer secondary contributes such as physical activity or tourists' emotions. Moreover, $15 \%$ of the studies reported the implementation of crowdsensing mechanisms to identify safety incidents, collect and share data related to the environmental conditions of the city, and to conduct participatory sensing campaigns and to determine the quality of the city routes.

In general, the studies failed to present evidence about how data privacy, integrity, and confidentiality are guaranteed, as well as how to deal with the lack of quality and accuracy of the gathered data and with the standardization, interoperability, and aggregation of heterogeneous data sources. Also, technical details of the sensing devices, communications networks, computing infrastructures and reasoning algorithms were, in general, poorly described.
Concerning the development stages of the applications being reported (i.e., the third research question), most of the studies included a performance evaluation of the respective applications or some of their components, such as a specific algorithm, while some of them were in an early development stage (i.e., requirements' elicitation). Just $15 \%$ of the studies included a user-centred evaluation, either a minimally working version of the applications (i.e., $[86,94,97])$ or a real-world evaluation by end users in their daily context during a certain period (i.e., [96]). Therefore, this systematic review of the literature shows that the applications reported by the included studies have a low maturity level and are still far from consolidated solutions, which was also identified by other studies related to smart cities' applications (e.g., [55]).

Given that smart cities are the subject of interest of countless researchers all over the world, it would be expected the inclusion of a larger number of studies. Twenty-seven studies represent a small number when compared to all the scientific production related to smart cities. One might think that this small number resulted from a narrow choice of the databases and keywords that were used. However, two of the databases being used, Scopus and Web of Science, are two well-reputed scientific indexing a huge number of scientific journals and conferencing proceedings that partially overlap publishers' databases (e.g., ACM Digital Library, Science Direct, SpringerLink or even IEEE Xplore) and allow a significant coverage of academic publications. Moreover, in terms of the keywords of the search queries, although in a previous work [34] a different search approach was used (i.e., a broad database search of publications having in their title, 
abstract or keywords, variations of the expression 'smart city' followed by a manual search among of the retrieved studies of the ones related to smart cities applications using context-aware features), a similar number of studies were included (except for studies published in 2020 that were not included in our previous work). However, a limitation can be foreseen in terms of only using the expression 'smart city', since other expressions (e.g., 'digital city' or 'intelligent city') are also used in the scientific literature. Even so, considering bibliometric analysis (e.g., $[10,20])$ or literature reviews related to the definitions of smart cities (e.g., [8]) the expression 'smart city' is the most used one. Therefore, in terms of academic research, the small number of included studies might indicate that the research effort to take advantage of the smart cities infrastructures to implement concrete context-aware applications is not very representative within smart cities' research.

However, this result cannot lead to the interpretation that there is no fundamental research in terms of context-aware and smart cities since the analysis carried out focused on the implementation of concrete applications. In fact, a significant number of studies were excluded from the screening phases because despite being related to smart cities and context-awareness, their focus was not on the development of concrete applications. Therefore, the number of basic research studies related to contextawareness and smart cities may considerably differ from the number of studies included in this review. However, this issue deserves further analysis, since, contrary to other technologies (e.g., loT, blockchain, fog computing, edge computing, data analytics or machine learning) it is not possible to identify terms related to context-awareness in certain reviews that compare the frequency of terms related to the development of smart cities (e.g., $[10,20])$. Additionally, since this review was specifically focused on smart city applications, it did not include those studies focused on context-awareness applications whose development was not performed in the context of smart cities (e.g., their authors did not consider the concept smart city), but according to the perspectives of other research areas (e.g., mobile health [109]). Moreover, since the focus was the peer-reviewed scientific publications, it is not possible to draw conclusions about non-peer reviewed documents (e.g., technical reports or industrial solutions).

Smart cities developments are spread all over the world $[8,10,19,20,27]$, although Europe stands out in terms of scientific productivity $[10,20]$. Therefore, it is not surprising that Europe is the geographic area with the highest number of contributions in terms of included studies. However, it was not expected the low contribution of countries such as USA, People's Republic of China and India that are important contributors in terms of scientific publications related to smart cities [10, 20]. Additionally, the small number of studies involving multinational teams suggest that are not being created synergies between researchers based at different countries, namely based at different Member States of the European Union.

The framework proposed by Giffinger et al. $[5,6]$ was adequate to classify the included studies. Except for smart people, applications were identified for all other areas domains of this framework. The smart people topic is relevant within smart city research [54], and its absence might be explained by the fact that context related to smart people domain is probable more dependent of personal factors (e.g., the engagement of the individuals on life-long learning programs might be dependent of their occupation, lack of personal accomplishment and satisfaction or lack of confidence in learning) than sensing data gathered by the smart city infrastructures. In fact, Neirotti et al. [21] when considering the application domains relevant to the topic of urban development, divided these application domains into hard and soft domains, in accordance with the importance of IT as key enabling factors. According to this idea, which was followed by other authors (e.g., $[8,10])$, environment, transport, mobility, and logistics, healthcare and public security are classified as hard domains, while education and culture, social inclusion and welfare, or economy are classified as soft domains [21]. In this respect, smart people and smart economy, the two less representative domains in this systematic review (i.e., the first with zero applications and the second with two applications), correspond to soft domains that are related to a lower importance of IT as enabling factors.

The context-aware features are in accordance with what is expected from the definitions of Abowd et al. [31] in terms passive context-aware applications that can be personalized, although active applications were not identified. Location recognition was the most representative primary context attribute, which was, in some studies considered together with activity recognition. This is in line with the findings presented by Nascimento et al. [32]. In turn, speed, physical activity, points of interest, stress, tourists' emotions, or the number of individuals inside a store were identified as secondary context attributes.

Using sensors to constantly monitor individuals has the potential to put their privacy at risk, due to the communication of personal data [55]. Therefore, secure data transmission and the guarantee that the stored data would only be accessed by individuals who are authorized are important requirements [33]. If these requirements are not satisfied, data such as the location of an individual at a given time might be used for nefarious purposes (e.g., to know when and for how long the individuals are out of their homes). Despite the importance of data privacy, integrity, and confidentiality, namely in terms of research (e.g., $[33,45])$, considering the included studies, these 
issues were not conveniently addressed. Moreover, other issues such as the quality and accuracy of the gathered data or mechanisms to deal with the standardization, interoperability and aggregation of heterogeneous data sources were not considered. Also, technical details of the sensing devices, communications networks, computing infrastructures and reasoning algorithms were, in general, poorly described. These results are not in line with relevant research related to smart cities, since in the current scientific literature topics such as big data analytics, data privacy and security, authentication, computing, and communication networks architectures assume the greatest attention [20]. A potential reason for this mismatch could be the fact that developing smart city applications is quite complex, their requirements have not yet been comprehensively extracted and systematized, including different scenarios and concerns, leading to a great variability in terms of design, implementation and required technologies, while, seldom, the research groups, namely academic research groups, do not have specialized knowledge to deal with all that complexity and variability.

Another result that deserves special attention is the low maturity level of the applications together with some flaws of the included studies revealed by methodological quality assessment. Also, the included studies failed to evaluate the impact of the proposed applications on the potential users, since only $15 \%$ of the studies implemented user-centred evaluations. However, in these user-centred evaluations the number of participants was reduced, and the measured outcomes were insufficient to determine the impact of the application when used in a daily basis. The lack of user-centred evaluations or their poor methodological quality can be considered a major barrier for the dissemination of the applications being developed and the future work must pay special to this issue.

A possible explanation for the insufficient assessment of the developed applications is that the development and effective validation of smart cities applications requires not only various types of resources, as mentioned before, (e.g., technologies and physical or virtual infrastructures) but also a diversity of stakeholders. Despite the existence of models aiming to optimize smart city implementations (e.g., [56]), the coordination of these resources and stakeholders requires experience and a large amount of effort. Most probable, a significant number of researchers are not aware of these challenges when they start the development of smart city applications.

Although the authors tried, in methodological terms, to follow rigorous procedures in terms of the selection of the studies and the extraction of data, it is always possible to point out limitations about both the chosen keywords and the databases that were used in the research and even the judgement of the authors when screening the articles.
Likewise, since a significant number of the included studies were published in conference proceedings, there will certainly be similar studies that have not been included because non-indexed conferences were not considered. Furthermore, the reliance solely on the English language may reduce the number of studies considered in the analysis. Finally, grey literature (e.g., technical reports or industrial solutions) was not considered in this review and that this can be seen as a gap of some significance, since it is assumed that there are many local field projects that are not published in scientific articles, but which will be reported in limited announcements (e.g., bulletins from city councils).

\section{Conclusion}

The study reported by this article aimed to review and analyse the state-of-the-art of the context-aware applications supported by smart cities' infrastructures. Relevant contributions were identified aiming to provide applications related to public health, tourism experience, urban mobility, active citizenship, shopping experience, management of urban infrastructures, public alerts, recommenders, and smart environments. Moreover, it is foreseen that the number of studies related to the topic will increase in the future, since the research effort increased over the years and $74 \%$ of the studies were published since 2017 . The included studies reported the use of different types of sensors are being used to acquire primary context attributes (i.e., location, activity, and environment) and secondary context attributes (i.e., speed, physical activity, points of interest, stress, and tourists' emotions) to support passive context-aware applications.

Big data analytics, data privacy and security, authentication, data standardization and integration, computing and communication networks architectures and protocols (i.e., 5G networks), loT implementation are, among others, important topics in the current smart city research. Surprisingly, these topics are almost absent in the set of the included studies. Moreover, technical details of both the sensors and the reasoning algorithms were poorly described by the included studies.

In general, the studies did not consider the requirements of the potential users, and only $15 \%$ studies presented experimental set-up to assess the proposed applications with end-users (although the respective experimental designs exhibited limitations). The remainder studies proposed concepts, architectures, and proofof-concepts prototypes.

Therefore, based on the findings of this systematic literature, it is possible to conclude that there is a lack of maturity of the developed applications (evidenced by the 
lack of user-centred evaluations and the difficulty in integrating important technologies being developed for smart cities), which constitutes a major barrier to their dissemination. Since a considerable investment is being made to bring together smart city stakeholders, including industry, for creating market-ready solutions, the low maturity level of the developments is a major gap on the current research related to context-aware applications requiring smart cities' infrastructures. This study evidences the poor incorporation in the specific topic of this systematic review, of the knowledge and solutions generated by the research related to other smart cities' topics, as well as the lack of robust experimental set-ups to evaluate impact of the applications being developed.

Funding This work was financially supported by National Funds through FCT—Fundação para a Ciência e a Tecnologia, I.P., under the project UI IEETA: UID/CEC/00127/2021.

\section{Declarations}

Conflicts of interest The authors have no conflicts of interest to declare that are relevant to the content of this article.

Open Access This article is licensed under a Creative Commons Attribution 4.0 International License, which permits use, sharing, adaptation, distribution and reproduction in any medium or format, as long as you give appropriate credit to the original author(s) and the source, provide a link to the Creative Commons licence, and indicate if changes were made. The images or other third party material in this article are included in the article's Creative Commons licence, unless indicated otherwise in a credit line to the material. If material is not included in the article's Creative Commons licence and your intended use is not permitted by statutory regulation or exceeds the permitted use, you will need to obtain permission directly from the copyright holder. To view a copy of this licence, visit http://creativecommons. org/licenses/by/4.0/.

\section{References}

1. Hoffman MC (2020) Smart cities: a review of the most recent literature. Inf Policy 27(1):3-35. https://doi.org/10.22693/NIAIP. 2020.27.1.003

2. Heynen $H$ (2016) Lutopia: an ideal city in an ideal world. In: Achten V, Bouckaert G, Schokkaert E (eds) A truly golden handbook': the scholarly quest for Utopia. Leuven University Press, Leuven, pp 332-348

3. Cocchia A (2014) Smart and digital city: a systematic literature review. In: Dameri R, Rosenthal-Sabroux C (eds) Smart city progress in IS. Springer, Berlin, pp 13-43. https://doi.org/10.1007/ 978-3-319-06160-3_2

4. Nesti G (2020) Defining and assessing the transformational nature of smart city governance: Insights from four European cases. Int Rev Adm Sci 86(1):20-37. https://doi.org/10.1177/ 0020852318757063
5. Giffinger R, Pichler-Milanović N (2007) Smart Cities: ranking of European medium-sized cities. Vienna University of Technology, Vienna

6. Giffinger R, Haindlmaier G (2010) Smart cities ranking: an effective instrument for the positioning of the cities? ACE Archit City Environ 4(12):7-26

7. Santinha G, Dias A, Rodrigues M, Queirós A, Rodrigues C, Rocha NP (2019) How do smart cities impact on sustainable urban growth and on opportunities for entrepreneurship? Evidence from Portugal: the case of Águeda. In: Cagica Carvalho L, Rego C, Lucas M, Sánchez-Hernández M, Backx Noronha Viana A (eds) New paths of entrepreneurship development. Studies on entrepreneurship, structural change and industrial dynamics. Springer, pp 31-53. https://doi.org/10.1007/978-3-319-96032-6

8. Albino V, Berardi U, Dangelico RM (2015) Smart cities: definitions, dimensions, performance, and initiatives. J Urban Technol 22(1):3-21. https://doi.org/10.1080/10630732.2014.942092

9. Dirks S, Gurdgiev C, Keeling M (2010) Smarter Cities for smarter growth: how cities can optimize their systems for the talentbased economy. Somers, IBM Global Business Services

10. Bajdor P, Starostka-Patyk M (2021) Smart City: a bibliometric analysis of conceptual dimensions and areas. Energies 14(14):4288. https://doi.org/10.3390/en14144288

11. Nam T, Pardo TA (2011) Conceptualizing smart city with dimensions of technology, people, and institutions. In: Proceedings of the 12th annual international digital government research conference: digital government innovation in challenging times, pp 282-291. https://doi.org/10.1145/2037556.2037602.

12. Chourabi H, Nam T, Walker S, Gil-Garcia JR, Mellouli S, Nahon K, et al (2012) Understanding smart cities: an integrative framework. In: 2012 45th Hawaii international conference on system sciences. IEEE, pp 2289-2297. https://doi.org/10.1109/HICSS. 2012.615

13. Anthopoulos L, Janssen M, Weerakkody V (2019) A unified smart city model (USCM) for Smart City conceptualization and benchmarking. In: Smart cities and smart spaces: concepts, methodologies, tools, and applications. IGI Global: Hershey, Pennsylvania. https://doi.org/10.4018/978-1-5225-7030-1. ch011

14. Nilssen M (2019) To the smart city and beyond? Developing a typology of smart urban innovation. Technol Forecast Soc Chang 142:98-104. https://doi.org/10.1016/j.techfore.2018.07. 060

15. Sharifi A (2019) A critical review of selected smart city assessment tools and indicator sets. J Clean Prod 233:1269-1283. https://doi.org/10.1016/j.jclepro.2019.06.172

16. Vishnivetskaya A, Alexandrova E (2019) 'Smart city' concept. Implementation practice. In: IOP conference series: materials science and engineering, vol. 497, no. 1. IOP Publishing, $p$ 12019. https://doi.org/10.1088/1757-899X/497/1/012019.

17. The IEEE smart cities initiative (Flyer). https://smartcities.ieee. org/images/files/pdf/IEEE_Smart_Cities-_Flyer_Nov_2017.pdf. Aaccessed 10 Dec 2021

18. Betis G, Larios VM, Petri D, Wu X, Deacon A, Hayar A (2018) The IEEE smart cities initiative-accelerating the smartification process for the 21st century cities [point of view]. Proc IEEE 106(4):507-512. https://doi.org/10.1109/JPROC.2018.2814239

19. Bibri SE, Bibri KJ, S. E., \& Krogstie, J. (2017) Smart sustainable cities of the future: an extensive interdisciplinary literature review. Sustain Cities Soc 31:183-212. https://doi.org/10.1016/j.scs. 2017.02.016

20. Sharifi A, Allam Z, Feizizadeh B, Ghamari H (2021) Three decades of research on smart cities: mapping knowledge structure and trends. Sustainability 13(13):7140. https://doi.org/10.3390/ su 13137140 
21. Neirotti P, De Marco A, Cagliano AC, Mangano G, Scorrano F (2014) Current trends in Smart City initiatives: some stylised facts. Cities 38:25-36. https://doi.org/10.1016/j.cities.2013.12. 010

22. Purnomo F, Prabowo H (2016) Smart city indicators: a systematic literature review. J Telecommun Electr Comput Eng JTEC 8(3):161-164

23. Clarinval A, Simonofski A, Vanderose B, Dumas B (2020) Public displays and citizen participation: a systematic literature review and research agenda. Transf Gov People Process Policy 15(1):1-35. https://doi.org/10.1108/TG-12-2019-0127

24. Malek JA, Lim SB, Yigitcanlar T (2021) Social inclusion indicators for building citizen-centric smart cities: a systematic literature review. Sustainability 13(1):376. https://doi.org/10.3390/su130 10376

25. Khatoun R, Zeadally S (2016) Smart cities: concepts, architectures, research opportunities. Commun ACM 59(8):46-57. https://doi.org/10.1145/2858789

26. Ahad MA, Paiva S, Tripathi G, Feroz N (2020) Enabling technologies and sustainable smart cities. Sustain Cities Soc 61:102301. https://doi.org/10.1016/j.scs.2020.102301

27. Silva BN, Khan M, Han K (2018) Towards sustainable smart cities: a review of trends, architectures, components, and open challenges in smart cities. Sustain Cities Soc 38:697-713. https:// doi.org/10.1016/j.scs.2018.01.053

28. Lytras MD, Visvizi A (2018) Who uses smart city services and what to make of it: Toward interdisciplinary smart cities research. Sustainability 10(6):1998. https://doi.org/10.3390/ su10061998

29. Bibri SE, Krogstie J (2016) On the social shaping dimensions of smart sustainable cities: a study in science, technology, and society. Sustain Cities Soc 29:219-246. https://doi.org/10. 1016/j.scs.2016.11.004

30. Schilit BN, Theimer MM (1994) Disseminating active map information to mobile hosts. IEEE Netw 8(5):22-32. https://doi.org/ 10.1109/65.313011

31. Abowd GD, Dey AK, Brown PJ, Davies N, Smith M, Steggles P (1999) Towards a better understanding of context and contextawareness. In Gellersen HW (eds) Handheld and ubiquitous computing. HUC 1999. Lecture Notes in Computer Science, vol 1707. Springer. https://doi.org/10.1007/3-540-48157-5_29

32. do Nascimento LV, Machado GM, Maran V, de Oliveira JPM (2021) Context recognition and ubiquitous computing in smart cities: a systematic mapping. Computing 103(5):801-825. https://doi.org/10.1007/s00607-020-00878-7

33. Cui L, Xie G, Qu Y, Gao L, Yang Y (2018) Security and privacy in smart cities: challenges and opportunities. IEEE Access 6:46134-46145. https://doi.org/10.1109/ACCESS.2018.28539 85

34. Rocha NP, Dias A, Santinha G, Rodrigues M, Rodrigues C, Queirós A (2021) Smart cities: drivers to increase context-awareness based on a systematic review of the literature. In: Rocha Á, Adeli H, Dzemyda G, Moreira F, Ramalho Correia AM (eds) Trends and applications in information systems and technologies. WorldCIST 2021. Advances in intelligent systems and computing, vol 1367. Springer. https://doi.org/10.1007/978-3-030-72660-7_58

35. Perera C, Zaslavsky A, Christen P, Georgakopoulos D (2013) Context aware computing for the internet of things: a survey. IEEE Commun Surv Tutor 16(1):414-454. https://doi.org/10.1109/ SURV.2013.042313.00197

36. Yin C, Xiong Z, Chen H, Wang J, Cooper D, David B (2015) A literature survey on smart cities. Science China Inf Sci 58(10):1-18. https://doi.org/10.1007/s11432-015-5397-4

37. Vahdat-Nejad H, Ramazani A, Mohammadi T, Mansoor W (2016) A survey on context-aware vehicular network applications. Veh
Commun 3:43-57. https://doi.org/10.1016/j.vehcom.2016.01. 002

38. Haruna K, Akmar Ismail M, Suhendroyono S, Damiasih D, Pierewan AC, Chiroma H, Herawan T (2017) Context-aware recommender system: a review of recent developmental process and future research direction. Appl Sci 7(12):1211. https://doi.org/ 10.3390/app7121211

39. Mora L, Bolici R, Deakin M (2017) The first two decades of smart-city research: a bibliometric analysis. J Urban Technol 24(1):3-27. https://doi.org/10.1080/10630732.2017.1285123

40. Capurso N, Mei B, Song T, Cheng X, Yu J (2018) A survey on key fields of context awareness for mobile devices. J Netw Comput Appl 118:44-60. https://doi.org/10.1016/j.jnca.2018.05.006

41. Soomro K, Bhutta MNM, Khan Z, Tahir MA (2019) Smart city big data analytics: an advanced review. Wiley Interdiscip Rev Data Min Knowl Discov 9(5):e1319. https://doi.org/10.1002/widm. 1319

42. Pacheco Rocha N, Dias A, Santinha G, Rodrigues M, Queirós A, Rodrigues C (2019) Smart cities and healthcare: a systematic review. Technologies 7(3):58. https://doi.org/10.3390/techn ologies7030058

43. Ismagilova E, Hughes L, Dwivedi YK, Raman KR (2019) Smart cities: advances in research-an information systems perspective. Int J Inf Manage 47:88-100. https://doi.org/10. 1016/j.ijinfomgt.2019.01.004

44. Sang Z, Li K (2019) ITU-T standardisation activities on smart sustainable cities. IET Smart Cities 1(1):3-9. https://doi.org/ 10.1049/iet-smc.2019.0023

45. Ahmed S, Shah MA, Wakil K (2020) Blockchain as a trust builder in the smart city domain: a systematic literature review. IEEE Access 8:92977-92985. https://doi.org/10.1109/ ACCESS.2020.2993724

46. Kong L, Liu Z, Wu J (2020) A systematic review of big databased urban sustainability research: state-of-the-science and future directions. J Clean Prod 273:123142. https://doi.org/ 10.1016/j.jclepro.2020.123142

47. Loos E, Sourbati M, Behrendt F (2020) The role of mobility digital ecosystems for age-friendly urban public transport: a narrative literature review. Int J Environ Res Public Health 17(20):7465. https://doi.org/10.3390/ijerph17207465

48. Lai CS, Jia Y, Dong Z, Wang D, Tao Y, Lai QH, Wong R, Zobaa A, Wu R, Lai LL (2020) A review of technical standards for smart cities. Clean Technol 2(3):290-310. https://doi.org/10.3390/ cleantechnol2030019

49. Anthony Jnr B (2021) Managing digital transformation of smart cities through enterprise architecture-a review and research agenda. Enterp Inf Syst 15(3):299-331. https://doi. org/10.1080/17517575.2020.1812006

50. Hajjaji Y, Boulila W, Farah IR, Romdhani I, Hussain A (2021) Big data and loT-based applications in smart environments: a systematic review. Comput Sci Rev 39:100318. https://doi. org/10.1016/j.cosrev.2020.100318

51. De Nicola A, Villani ML (2021) Smart city ontologies and their applications: a systematic literature review. Sustainability 13(10):5578. https://doi.org/10.3390/su13105578

52. Kim H, Choi H, Kang H, An J, Yeom S, Hong T (2021) A systematic review of the smart energy conservation system: From smart homes to sustainable smart cities. Renew Sustain Energy Rev 140:110755. https://doi.org/10.1016/j.rser.2021. 110755

53. Paiva S, Ahad MA, Tripathi G, Feroz N, Casalino G (2021) Enabling technologies for urban smart mobility: recent trends. Oppor Chall Sens 21(6):2143. https://doi.org/10.3390/s2106 2143

54. Omotayo T, Moghayedi A, Awuzie B, Ajayi S (2021) Infrastructure elements for smart campuses: a bibliometric analysis. 
Sustainability 13(14):7960. https://doi.org/10.3390/su131 47960

55. Rocha NP, Bastardo R, Pavão J, Santinha G, Rodrigues M, Rodrigues $C$ et al (2021) Smart Cities' applications to facilitate the mobility of older adults: a systematic review of the literature. Appl Sci 11(14):6395. https://doi.org/10.3390/app11146395

56. Taratori R, Fiscal PR, Pacho MA, Koutra S, Pareja-Eastaway M, Thomas D (2021) Unveiling the evolution of innovation ecosystems: an analysis of triple, quadruple and quintuple helix model innovation systems in European case-studies. Sustainability 13(14):7582. https://doi.org/10.3390/su13147582

57. Moher D, Liberati A, Tetzlaff J, Altman DG (2010) Preferred reporting items for systematic reviews and meta-analyses: the PRISMA statement. Int J Surg 8(5):336-341

58. Xiao Y, Watson M (2019) Guidance on conducting a systematic literature review. J Plan Educ Res 39(1):93-112. https://doi.org/ 10.1177/073945617723971

59. Martín-Martín A, Orduna-Malea E, Thelwall M, López-Cózar ED (2018) Google Scholar, Web of Science, and Scopus: a systematic comparison of citations in 252 subject categories. J Informet 12(4):1160-1177. https://doi.org/10.1016/j.joi.2018. 09.002

60. Singh VK, Singh P, Karmakar M, Leta J, Mayr P (2021) The journal coverage of Web of Science, Scopus and Dimensions: a comparative analysis. Scientometrics 126(6):5113-5142. https://doi. org/10.1007/s11192-021-03948-5

61. Shahin M, Liang P, Babar MA (2014) A systematic review of software architecture visualization techniques. J Syst Softw 94:161-185. https://doi.org/10.1016/j.jss.2014.03.071

62. Yang L, Zhang H, Shen H, Huang X, Zhou X, Rong G, Shao D (2020) Quality assessment in systematic literature reviews: a software engineering perspective. Inf Softw Technol 130:106397. https://doi.org/10.1016/j.infsof.2020.106397

63. Dey AK (2000) Providing architectural support for building context-aware applications. Georgia Institute of Technology, Atlanta

64. Sezer OB, Dogdu E, Ozbayoglu AM (2017) Context-aware computing, learning, and big data in internet of things: a survey. IEEE Internet Things J 5(1):1-27. https://doi.org/10.1109/JIOT. 2017.2773600

65. Cabrera C, Palade A, White G, Clarke S (2020) An urban-driven service request management model. In: 2020 IEEE international conference on pervasive computing and communications (PerCom), pp 1-7. IEEE. https://doi.org/10.1109/PerCom45495. 2020.9127371

66. Celaya-Echarri M, Azpilicueta L, Lopez-Iturri P, Rodríguez-Corbo FA, Ramos V, Falcone F (2020) Analysis of Personal RF-EMF radiation exposure within public transportation buses. In: 2020 IEEE international symposium on antennas and propagation and North American radio science meeting. IEEE, pp 11531154. https://doi.org/10.1109/IEEECONF35879.2020.9329729

67. Al Harbi S, Halabi T, Bellaiche M (2020) Fog computing security assessment for device authentication in the internet of things. In: 2020 IEEE 22nd international conference on high performance computing and communications; IEEE 18th international conference on smart city; IEEE 6th international conference on data science and systems (HPCC/SmartCity/DSS). IEEE, pp 1219-1224. https://doi.org/10.1109/HPCC-SmartCity-DSS50 907.2020 .00202

68. Chen B, Xie H (2020) A context-aware collaborative filtering recommender system based on GCNs. In: 2020 international conference on intelligent transportation, big data and smart city (ICITBS). IEEE, pp 703-706. https://doi.org/10.1109/ICITB S49701.2020.00155
69. Reddy KHK, Luhach AK, Pradhan B, Dash JK, Roy DS (2020) A genetic algorithm for energy efficient fog layer resource management in context-aware smart cities. Sustain Cities Soc 63:102428. https://doi.org/10.1016/j.scs.2020.102428

70. Taskin D, Yazar S (2020) A Long-range context-aware platform design for rural monitoring with loT In precision agriculture. Int J Comput Commun Control. https://doi.org/10.15837/ijccc. 2020.2.3821

71. Lin H, Luo Z, Li W, Chen Y, Wang C, Li J (2020) Adaptive pyramid context fusion for point cloud perception. IEEE Geosci Remote Sens Lett. https://doi.org/10.1109/LGRS.2020.3037509

72. Wang J, Wu J, Wang Z, Gao F, Xiong Z (2019) Understanding urban dynamics via context-aware tensor factorization with neighboring regularization. IEEE Trans Knowl Data Eng 32(11):2269-2283. https://doi.org/10.1109/TKDE.2019.29152 31

73. Aguilar J, Jerez M, Mendonça M, Sánchez M (2020) Performance analysis of the ubiquitous and emergent properties of an autonomic reflective middleware for smart cities. Computing 102(10):2199-2228. https://doi.org/10.1007/ s00607-020-00799-5

74. Fernández PJ, Santa J, Skarmeta AF (2020) Hybrid positioning for smart spaces: proposal and evaluation. Appl Sci 10(12):4083. https://doi.org/10.3390/app10124083

75. Zhao L, Peng Z (2020) Analysis and design of a context-aware smart home system. In: 2020 international conference on intelligent transportation, big data and smart city (ICITBS). IEEE, pp 716-719. https://doi.org/10.1109/ICITBS49701.2020.00158

76. Sun P, Yuepeng E, Li T, Wu Y, Ge J, You J, Wu B (2020) Contextaware learning for anomaly detection with imbalanced log data. In: 2020 IEEE 22nd international conference on high performance computing and communications; IEEE 18th international conference on smart city; IEEE 6th international conference on data science and systems (HPCC/SmartCity/DSS). IEEE, pp 449-456. https://doi.org/10.1109/HPCC-SmartCity-DSS50 907.2020.00055

77. Soic R, Vukovic M, Skocir P, Jezic G (2020) Context-aware service orchestration in smart environments. In: Agents and multi-agent systems: technologies and applications 2019. Springer, Singapore, pp 35-45. https://doi.org/10.1007/ 978-981-13-8679-4_3

78. Du Y, Issarny V, Sailhan F (2020) In-network collaborative mobile crowdsensing. In: 2020 IEEE international conference on pervasive computing and communications workshops (PerCom workshops). IEEE, pp 1-2. https://doi.org/10.1109/PerComWork shops48775.2020.9156268

79. Colace F, De Santo M, Greco L, Lemma S, Lombardi M, Moscato V, Picariello A (2014) A context-aware framework for cultural heritage applications. In: 2014 Tenth international conference on signal-image technology and internet-based systems. IEEE, pp 469-476. https://doi.org/10.1109/SITIS.2014.14

80. Matsuda Y, Fedotov D, Takahashi Y, Arakawa Y, Yasumoto K, Minker W (2018) Emotour: multimodal emotion recognition using physiological and audio-visual features. In: Proceedings of the 2018 ACM international joint conference and 2018 international symposium on pervasive and ubiquitous computing and wearable computers. ACM, pp 946-951. https://doi.org/ $10.1145 / 3267305.3267687$

81. Casino F, Patsakis C, Batista E, Postolache O, Martínez-Ballesté A, Solanas A (2018) Smart healthcare in the loT era: a contextaware recommendation example. In: 2018 International Symposium in Sensing and Instrumentation in IOT Era (ISSI). IEEE, pp 1-4. https://doi.org/10.1109/ISSI.2018.8538106 
82. Alghamdi W, Shakshuki E, Sheltami TR (2012) Context-aware driver assistance system. Procedia Comput Sci 10:785-794. https://doi.org/10.1016/j.procs.2012.06.100

83. Salem M, Deva B, Salem M, Deva B (2013) 3rd party geolocation messaging: a positioning enabler middleware for realizing context-aware polling. In: 2013 International conference on MOBILe wireless MiddleWARE, operating systems, and applications. IEEE, pp 100-109. https://doi.org/10.1109/Mobilware. 2013.10

84. Banerjee S, Mukherjee D, Misra P (2013) 'What affects me?' a smart public alert system based on stream reasoning. In: Proceedings of the 7th international conference on ubiquitous information management and communication. ACM, pp 1-10. https://doi.org/10.1145/2448556.2448578

85. Khan Z, Kiani SL, Soomro K (2014) A framework for cloudbased context-aware information services for citizens in smart cities. J Cloud Comput 3(1):1-17. https://doi.org/10.1186/ s13677-014-0014-4

86. Delmastro F, Arnaboldi V, Conti M (2016) People-centric computing and communications in smart cities. IEEE Commun Mag 54(7):122-128. https://doi.org/10.1109/MCOM.2016.7509389

87. Biondi S, Monteleone S, La Torre G, Catania V (2016) A contextaware smart parking system. In: 12th International conference on signal-image technology and internet-based systems (SITIS). IEEE, pp 450-454. https://doi.org/10.1109/SITIS.2016.76

88. Kim K, Kim H, Kim SK, Jung JY (2016) i-RM: an intelligent risk management framework for context-aware ubiquitous cold chain logistics. Expert Syst Appl 46:463-473. https://doi.org/ 10.1016/j.eswa.2015.11.005

89. Goel D, Chaudhury S, Ghosh H (2017) An loT approach for context-aware smart traffic management using ontology. In: Proceedings of the international conference on web intelligence. ACM, pp 42-49. https://doi.org/10.1145/3106426.3106499

90. Khoi NM, Rodríguez-Pupo LE, Casteleyn S (2017) Citizensea generic user-oriented participatory sensing framework. In: 2017 International conference on selected topics in mobile and wireless networking (MoWNeT). IEEE, pp 1-8. https://doi.org/ 10.1109/MoWNet.2017.8045954

91. Klimek R (2017) Context-aware and pro-active queue management systems in intelligent environments. In: 2017 Federated conference on computer science and information systems (FedCSIS). IEEE, pp 1077-1084. https://doi.org/10.15439/2017F 362

92. Das RB, Bozdog NV, Bal H (2017) Cowbird: a flexible cloudbased framework for combining smartphone sensors and iot. In: 5th IEEE international conference on mobile cloud computing, services, and engineering (MobileCloud). IEEE, pp 1-8. https://doi.org/10.1109/MobileCloud.2017.14

93. Casino F, Patsakis C, Batista E, Borràs F, Martínez-Ballesté A (2017) Healthy routes in the smart city: a context-aware mobile recommender. IEEE Softw 34(6):42-47. https://doi.org/10.1109/ MS.2017.4121209

94. Abu-Issa A, Nawawreh H, Shreteh L, Salman Y, Hassouneh Y, Tumar I, Hussein M (2017) A smart city mobile application for multitype, proactive, and context-aware recommender system. In: 2017 international conference on engineering and technology (ICET). IEEE, pp 1-5. https://doi.org/10.1109/ICEngTechnol. 2017.8308181

95. Garcia-de-Prado A, Ortiz G, Boubeta-Puig J, Corral-Plaza D (2018) Air4People: a smart air quality monitoring and contextaware notification system. J Univ Comput Sci 24(7):846-863

96. Matsuda Y, Fedotov D, Takahashi Y, Arakawa Y, Yasumoto K Minker W (2018) Emotour: Estimating emotion and satisfaction of users based on behavioral cues and audiovisual data. Sensors 18(11):3978. https://doi.org/10.3390/s18113978
97. Boletsis C, Chasanidou D (2018) Smart tourism in cities: Exploring urban destinations with audio augmented reality. In: Proceedings of the 11 th PErvasive technologies related to assistive environments conference. ACM, pp 515-521. https://doi.org/ 10.1145/3197768.3201549

98. Aarab Z, Elghazi A, Saidi R, Rahmani MD (2017) Toward a smart tourism recommender system: applied to tangier city. In: Ben Ahmed M, Boudhir A (eds) Innovations in smart cities and applications. SCAMS 2017. Lecture Notes in Networks and Systems, vol 37. Springer. https://doi.org/10.1007/978-3-31974500-8_59

99. Garzon SR, Walther S, Pang S, Deva B, Küpper A (2018) Urban air pollution alert service for smart cities. In: The 8th international conference on the internet of things, pp 1-8. ACM. https://doi. org/10.1145/3277593.3277599

100. Rehena Z, Janssen M (2018) Towards a framework for contextaware intelligent traffic management system in smart cities. In: Companion proceedings of the web conference 2018. ACM, pp 893-898. https://doi.org/10.1145/3184558.3191514

101. Haque MU, Zulfiqar H, Ahmed A, Ali Y (2021) A context-aware framework for modelling and verification of smart parking systems in urban cities. Concurr Comput Pract Exp 33(2):e5401. https://doi.org/10.1002/cpe.5401

102. Colace F, De Santo M, Lombardi M, Santaniello D (2019) CHARS: a cultural heritage adaptive recommender system. In: 1st ACM international workshop on technology enablers and innovative applications for smart cities and communities. ACM, pp 58-61. https://doi.org/10.1145/3364544.3364830

103. Fejzo O, Zaslavsky A, Saguna S, Mitra K (2019) Proactive context-aware loT-enabled waste management. In: Internet of things, smart spaces, and next generation networks and systems. Springer, pp 3-15. https://doi.org/10.1007/ 978-3-030-30859-9_1

104. Bastos D, Ribeiro J, Silva F, Rodrigues M, Santos R, Martins C et al (2019) Smartwalk mobile-a context-aware m-health app for promoting physical activity among the elderly. In: World conference on information systems and technologies. Springer, pp 829-838. https://doi.org/10.1007/978-3-030-16184-2_79

105. Ghose B, Rehena Z (2020) A mechanism for air health monitoring in smart city using context aware computing. Procedia Comput Sci 171:2512-2521. https://doi.org/10.1016/j.procs. 2020.04.272

106. Khan A, Ahmad A, Rahman AU, Alkhalil A (2020) A mobile cloud framework for context-aware and portable recommender system for smart markets. In: Smart infrastructure and applications. Springer, Cham, pp 283-309. https://doi.org/10.1007/ 978-3-030-13705-2_12

107. Lakehal A, Alti A, Laborie S, Roose P (2020) A semantic agile approach for reconfigurable distributed applications in pervasive environments. Int J Ambient Comput Intell (IJACI) 11(2):48-67. https://doi.org/10.4018/IJACl.2020040103

108. Schürholz D, Kubler S, Zaslavsky A (2020) Artificial intelligenceenabled context-aware air quality prediction for smart cities. J Clean Prod 271:121941. https://doi.org/10.1016/j.jclepro.2020. 121941

109. Abdellatif AA, Mohamed A, Chiasserini CF, Tlili M, Erbad A (2019) Edge computing for smart health: Context-aware approaches, opportunities, and challenges. IEEE Netw 33(3):196-203. https://doi.org/10.1109/MNET.2019.1800083

Publisher's Note Springer Nature remains neutral with regard to jurisdictional claims in published maps and institutional affiliations. 